\title{
Economic Effect of School Dropout in Bangladesh
}

\author{
Md Nazirul Islam Sarker, Min Wu, and Md Altab Hossin
}

\begin{abstract}
School dropouts have negative consequences for the social, political, environmental and economic development of a country. This study aims to determine the economic effect of school dropout in the context of Bangladesh. It also explores the factors associated with school dropout in Bangladesh. An extensive review of the literature has been performed especially on international peer-reviewed research articles. Studies have been assessed on some pre-defined domains like reasons for school dropout, social, economic, political, and environmental factor, government initiatives to reduce dropout, school's study environment, geographical factors, social norms and values, and expert opinion. The study reveals that school dropout is negatively related to economic development in Bangladesh. The study also explores that chronic poverty, parent's unwillingness, financial problem, school's poor infrastructure, biased social practice, lack of quality education, geographic isolation, unequal access to education, and security problems for girls are major causes of school dropout in Bangladesh. The study suggests that free education program, reducing paid coaching culture, lessening cost of private school, raising awareness of parents by teacher-parents relationship, improving school's infrastructure, ensuring equal access to education, providing quality training for teachers, provision of all related facilities should be ensured at the policy level by government's policymakers.
\end{abstract}

Index Terms-School dropout, factor, economic effect, education.

\section{INTRODUCTION}

Bangladesh is a populous country based on mainly rural villages. Since independence in 1971, the country has been facing challenges of poverty with high population growth, unemployment, high vulnerability to natural disaster and slow economic growth. Most of the challenges are beset with human resource development and inseparably linked with education [1]. It is a great concern for the nation that poverty is a major problem which faced by about half of the total population. The rural sector concentrates 93 percent of the very poor and 89 percent of the poor [2]. About 63 million are suffered from seasonal famine and unable to meet basic needs [3]. Among them, half portion faces extreme poverty with no land, no homestead, chronic diseases and no regular income. Human capital development may be a key to alleviate poverty. Youth, the most valiant and largest group in Bangladesh and historically, has constituted a great force in effecting progressive social, economic and political change. With their creativity, dynamism, and urge for the achievement of better life goals, they continue to form an enormous resource for national development. The youths are

Manuscript received April 15, 2018; revised August 29, 2018. This work was not supported by any funding body.

The authors are with School of Public Administration, Sichuan University, Chengdu, China (e-mail: sarker.scu@yahoo.com, wuminhelen@163.com). considered as a positive force for development and social transformation and no development endeavour will come into effect if their energies are not curbed and they are not encouraged to organize themselves to become an integral part of development efforts. With the enormous increase in the size of the youth population, the development potential of youth, their participation in income generating activities and the problems confronted have to be recognized [4]. If proper attention is not given to youth, or if they are excluded, unemployed, disorganized, exploited and lacking in hope of achieving their future life goals, the process of development and pathways of out of poverty will be severely affected. To face the emerging challenges of poverty and unemployment in rural areas, the time has never been better to measure the extent of participation, organize and invest for the rural youths, who are dropouts from the education system every year. The rural school dropout youth, who have already received learning from home, school, and workplace and hopefully able to contribute better than others as the tomorrow's productive workers, entrepreneurs and indeed as a responsible citizen [5].

Education is a tool which is necessary to become an independent nation. It is a vital tool which can alleviate poverty. It has a key role and extreme influential impact on all sphere of human life. Education is actually a top investment for a nation. School dropout is a harmful factor which affects so much in human capital development for a nation. According to the National Center for Education, school dropout means student leave the school without completing a certificate or equivalent credential. Productivity, social and economic development of a country largely depends on quality education [6]. Because it plays a vital role. The policymaker, administrator, and related authority do not pay proper attention to school dropout in a developing country. They also have no attention to improving the quality of education and preventing school dropout. According to UNESCO [7], dropping out is a major problem in the developing country where one thirty million children are suffered from this problem. It is actually a disaster in the education system. School dropout is a condition of discontinuation of education which mainly happened due to social, economic, political and environmental factors. It also means no completion of a specific degree or grade [8]. It mostly occurs in financially poor societies. Sometimes students are not attending class or cancelling the registration of school. Generally, it means that student discontinues their education from a primary school or high school without completion of a degree or a grade. It occurs irrespective of developing and developed countries but the rate of school dropout is higher in a developing country than a developed country [9]. Literature survey shows that the economic effect of school dropout is rarely studied and it has never been 
studied for Bangladesh case where the school dropout rate is remarkably high [10]. Considering the importance of the matter, the piece of research has been undertaken to study. The article attempted to address the questions like (i) what are the reasons for school dropout in Bangladesh? (ii) what is the economic effect of school dropout on the development of a country? (iii) what are the ways to minimize the school dropout? The question leads the research team to achieve the objectives like (i) to find out causes of student dropouts in Bangladesh; (ii) to determine the economic effects of school dropouts on the development of the country; and (iii) to explore the possible ways to reduce school dropouts in Bangladesh.

\section{Methodology}

This article mainly uses secondary sources. An extensive review of the literature has been performed especially on international peer-reviewed research articles [11]. A primary search has been conducted on Google scholar, web of science, researchgate, science direct, Springer link, and Scopus by using some important keywords like "economic, effect, school dropout, factor, Bangladesh". The population is primary and secondary school students and the outcome is the economic effect of dropout. Abstract or title screening and quality assessment have been performed by the researchers. Studies have been assessed on some pre-defined domains like reasons for school dropouts, social factor, economic factor, political factor, environmental factor, government initiatives to the reduce dropout, school's study environment, geographical factors, social norms and values, and expert opinion. Only perplexing articles were included for final analysis. Among 151 research articles, 57 have been quality assessed. The data collection and analysis for this study have been done from July to August 2017.

\section{PRESENT CONDITIONS OF SCHOOL Dropout IN BANGLADESH}

Educational opportunities in the rural areas of Bangladesh were limited in the past. The development efforts mostly aimed at infrastructural development neglecting quality education and human resource development [12]. In the near past, considerable progress has been made in the provision of educational opportunities in rural areas and it is due to high government sectoral priorities on education and constitutional obligation. Even that, the education in Bangladesh is not available to all and it is rural male and the female youth who are most affected by inefficiency in the educational system. The school dropout rate in primary and secondary level is high though the government has taken many initiatives and actions. The reducing rate of school dropout is not at the expected level. The major reasons for school dropout are chronic poverty, expensive study material, weak teaching system, costly private coaching, child marriage, and social insecurity [13]. Research shows that only $32 \%$ student retain up to higher secondary level while $68 \%$ dropout at school level in Bangladesh. Some initiative programs like a monthly stipend, school feeding action, and free textbook distribution are going on but the dropout rate is still high. According to BANBEIS (Bangladesh Bureau of Educational Information and Statistics), the school dropout rate is $38.3 \%$ and the major reasons of school dropout are poverty, child marriage in ultra-poor families, failing in examination and eve-teasing to school going girls. In the rural areas, early marriage and distance to an educational institution are major reasons for school dropout. According to the World Bank [14], poverty, poor technology system and poor base of students are the major reasons of school dropout in Bangladesh. The rate of school dropout happens at every class from class one to class five. It is also found that there is a big difference between the number of register student and actual exam appearing students at the terminal examination at primary level. According to the Ministry of Education of Bangladesh, the participant number was 22,72289 but passed only 208200 and failed 174207 students in the junior terminal examination in 2015. Not only that more than 100000 students had registration but did not fill up the form of examination [15]. According to BANBEIS [16], the enrollment rate is reduced about 400000 from 2014 to 2015 at the primary level. It is slightly reduced in 2015 than in 2014 but increased to a higher secondary level in 2015. The dropout rate was $41.59 \%$ in 2014 but it becomes $40.29 \%$ in 2015 at the secondary level. While the dropout rate was $21.37 \%$ in 2014 but increased to 22.70 in 2015 at higher secondary. The total students from primary to university level was 36646519 in 2015 where girls were about 18400637 that means girls are the half portion of a total number of students. The enrollment rate is high but the dropout rate is also a vulnerable level.

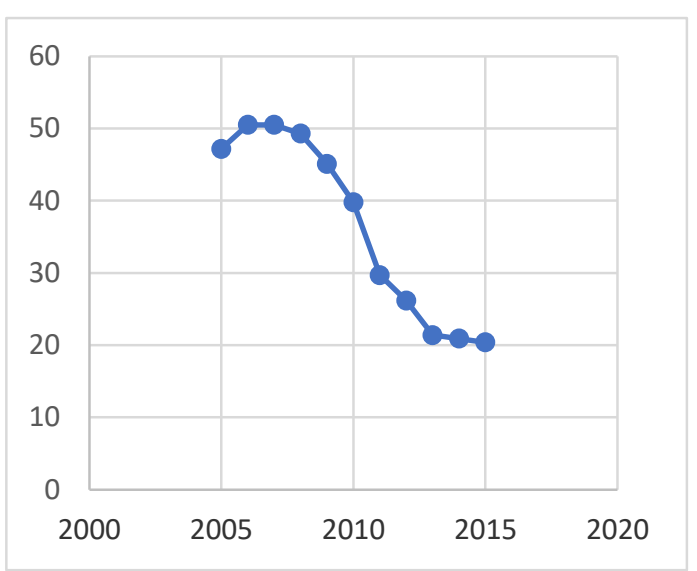

Fig. 1. Year wise percentage of school dropout rate in Bangladesh Source: [16].

Recent literature shows that $40 \%$ dropout is happened due to poverty and $37.5 \%$ of children do not like the schooling system. According to Hossain et al. [17], lower household income and food insecurity are the main reason for school dropout in Bangladesh. Not only that the school dropout households are suffering from many problems like unskilled labour work, almost no access to mass media or information source and electricity, no alternative income source and facing seasonal food insecurity. About $50 \%$ of girls are faced with early marriage and subsequently, drop out of school while only $2 \%$ of boys face the same problem [18]. On the other hand, boys are found to leave the school due to engage 
in income generating activities for bearing a household's livelihood while less number of girls engage themselves in income generating activities.

\section{REASONS BEHIND SCHOOL DROPOUT IN BANGLADESH}

\section{A. Poor Physical Condition}

The physical condition means a condition of the well-being of a student when all internal and external body parts are functioning well according to the requirement. An unhealthy student cannot learn well because of his physical barriers. If the physical condition is good, he/she can learn fast. The physical condition of the school going children is not the same everywhere in Bangladesh. The physical condition of city children is better than rural living children due to household income level. Some factors like malnutrition, poor health, chronic diseases and lack of motivation are also responsible for school dropout [19]. Generally, physical and psychological impediments are the major causes of school dropout in rural areas in Bangladesh. Nowadays government has already launched an autistic school for autistic children but access rate is very low due to long distance and ignorance of the people about the school. There is a possibility to drop out of school because of physical disability and malnutrition. Generally, disabled children cannot complete the full cycle of their schooling. The rate of disable children admission is very low and the dropout rate is high in Bangladesh. According to Hochfield et al. [20], public-private social investment contributed to reducing school dropout in Johannesburg, South Africa by introducing the school feeding program. Similarly, nutrition program is a good initiative to reduce mal-nutrition and short-term hunger and reduce school dropout. It also helps to increase the weight and capacity of activity and learning. Nutrition program also reduces children's chronic vulnerability which is occurred due to income inequality and chronic poverty [2].

\section{B. Biased Social Practice}

There is a biased social practice in the society of most of developing countries. People think that men are the earning member of the household, so it is wise to educate boys of a family. Whereas girls are only doing family affairs so no need to educate them. This value is existing in the rural societies in Bangladesh. Some other factor like child marriage, human trafficking, slavery, fostering and multiple household duties added bad influence on girl's school dropout. It seems like a system where education is necessary for boys but not for girls. Nowadays people are trying to break this norm. The enrollment rate of girls is increasing day by day in rural areas in Bangladesh. But at the same time, school dropout is increasing especially for girl's case than boys. Cabus and Witte [21] observed that Dutch vocational student left their school just before policy reform without any degree though they have without retention in grade. According to Crista et al. [22], there is no significant impact of technology access to initial enrollment, learning, repletion and school dropout. The school dropout rate is a little higher in the secondary stage. The education status of the family member has a great influence on children's study [23]. It is seen that mother's education has a more influence than other members. It acts as a predictive factor. The dropout rate is low where mothers are more educated.

\section{Lack of Quality of Education}

There are some factors which directly influence the quality of education like frequent absenteeism of teachers, long distance of school, poor educational and physical facilities. Income equality is a major influential factor in quality education. There are some factors of inequality in primary education like a misinterpretation of religion, socio-cultural norms, illiterate parents and almost no exception for girl's study [24]. The social economic class is another factor of poor quality education. Because the upper class of society can manage costly education for their children which is opposite in rural areas of Bangladesh. People having a lower class or lower income group are bound to send their children to the government school or NGO's school where less attention is paid by the concerned authority for maintaining quality education.

\section{Economic Hardship}

Economic hardship is a major problem for school dropout. About $31.5 \%$ people are living below the poverty line in Bangladesh. The livelihood is very hard for the people where the price hike of a daily necessary commodity is a regular matter. People are bound to spend their earning for purchasing essential commodity by reducing the cost of education. The study shows that $80 \%$ of earning is being used for buying essential food items for livelihood without saving any money at the rural as well as urban areas in Bangladesh [12]. Children are bound to leave their school and join to work for earning money for livelihood. Child labour is a very known word in Bangladesh where about $22.9 \%$ of the child labourer is doing life risky jobs to carry on the livelihood of their family. Garments industry of Bangladesh is an experience to get a large number of girl's enrollment where most of them are school dropout [25]. It usually happens after completion of primary education before completion of primary and secondary education for earning money to maintain the livelihood of their family.

\section{E. Geographic Isolation}

Bangladesh is a country of $1,47,000$ square kilometre but based on rural villages and full of rivers where about 230 rivers spread like a net with Riverine islands, coastal areas and mountainous areas. The access to education in these areas are smaller than other plain land areas [26]. The teachers and other regulatory bodies are not willing to do work in these areas. Besides all the administrative functions of educations are based on the city areas and eight divisional areas of Bangladesh. As a result, the most deprived people are living the riverine island and coastal areas in Bangladesh. They are characterized by income inequalities, poor communication, poor technology access, seasonal food insecurity and poor educational facilities. It is seen that most of the schools in riverine islands, coastal areas and mountainous areas frequently face teacher's absenteeism, proxy teachers (individual teach children on behalf of the main teacher) and no monitoring from concerned authority of 
the government [27]. These reasons are prominent for school dropout for school dropout in these areas.

\section{F. Parental Education and Family Factor}

Parental education has a significant effect on children's enrollment in school. The rate of illiterate parents are decreasing day by day, for example, it was $47.7 \%$ in 1998 but decreased to $33.3 \%$ in 2008 [28]. On the other hand, the net enrollment rate is increasing gradually. The educated parents are more conscious about the education of their children than illiterate parents. Mother's literacy is a great factor for children's education. Illiterate parents have less interest and less engagement to education-related activities, as a result, their children are more vulnerable to drop out than literate parent's children [29].

\section{G. Uncontrolled Population Growth and Unequal Access to Education}

Overpopulation is an important factor for school dropout. For example, a Barisal division of Bangladesh is doing better in high school enrollment due to its low rate of population growth than others. The proper initiative should be taken by the government to transform the population into human capital [15]. It will help to reduce school dropout.

\section{H. Early Marriage and Pregnancy of School Going Girl}

One of the most reason for girl's school dropout is early marriage in the rural areas. It is usually happened due to parent's hypergamic tendency and payment of dowry system [30]. Sometimes a parent wants to get relief by pushing their girls into marriage. This system of rural areas increases school dropout. Pregnancy is a major cause of school dropout in the rural areas in Bangladesh. Early marriage is a common phenomenon in rural areas of Bangladesh. Parents and relatives usually don't take any risk at the time of pregnancy, as a result, most of the rural girls are dropout during pregnancy. Proper counselling and quality improvement intervention can reduce the school dropout during pregnancy [31].

\section{Migration as a Cause of School Dropout}

Migration is a cause of school dropout in Bangladesh. Some people are migrated frequently for livelihood, their children are highly vulnerable to school dropout. Migration has been shown to be both positively and negatively related to school dropout [32]. Frequent migration influences the household and minimizes school attainment and the absence of a family member can increase the labour burden at home. In addition, sometimes it creates a culture within the household which stimulates children's negligence to attend school. Conversely, migration may have positive effects on reducing dropout. Remittances from such family members can offset inhibitive costs of education and inspire children to do their part and stay in school. Yi et al. [9] reported that policymakers usually considered upper secondary technical and vocational education and training as a key tool for poverty reduction and economic development in developing countries but evidence proved that it already faced high school dropout problem. Frequent migration is positively correlated to school dropout, poor quality learning, and poor academic performance.

\section{J. Effects of Relationship and Insecurity}

Friends and relatives have a great influence on school dropout. Literature suggests that friendship ties are important for school attendance. Sometimes parents are taking their children's education decision by influencing relatives. Children's are usually motivated by observing a friend's behaviour. There is a peer effect on school dropout in Bangladesh. In some cases, a student's identity and normative value are influenced by distant friends and relatives. There is a co-education system where boys and girls are studying together. So, there is a possibility to abuse sexually by teachers and fellow students. It is one of the major causes of dropout for girl student. Abuya et al. [33] found that sexual abuse and harassment are the major reasons for the girl's dropout in Bangladesh. Parents are always thinking about the safety of their children especially girl's. Girls are actually not safe at roads, schools, and markets due to massive eve-teasing, sexual harassment, and rape. The main reason is the failure of the government to ensure the law and order situation of the country.

\section{EFFECT OF SCHOOL DEVELOPMENT}

Because Education is a way to improve an individual's economic security as well as well-being [34]. It is a key tool for human resources development, economic development, the welfare of individuals, society $\&$ state and driven of economic transformation. Islam [35] mention that there are three key ways of the economic contribution of education like improving the productivity of labour, maximizing land and natural resources utilization and enhancing socio-economic empowerment. There is a long debate on the role of education in economic development. Human capital development is largely depending on investment in education. It brings a good and fastest result than other physical and social development. The investment on education usually bring a significant result on social well-being and economic development and also contribute to a skilled manpower society, improving life leading quality and reducing social inequality through adopting modern technology, knowledge and strong ethical background. The expenditure on education is increasing day by day in Bangladesh. The education expenditure rose to the 20470 crores in 2008 from the 73 crores in 1973. It shows a positive attention of the government on education. Subsequent, the GDP is also increasing like GDP was the 7575 crores in 1974 but increased to the 541919 in 2008 [36]. It is shown that GDP is increasing with the increased investment in the education sector. According to Islam [35], the investment in education and the enhancement of GDP of a country are positively related that means more investment to education brings more GDP. In every year, about $30 \%$ of students have left the school for various reason which creates a burden on their life as well as the economy of the country. The literacy rate of Bangladesh is lower than other developed countries in the world which show a poor economic development. As a rural-based country, the economy of Bangladesh is based on agriculture. It means that the fate of the people of Bangladesh cannot be changed without mentionable achievement in 
agriculture. The only way to develop the agriculture sector is education. Education can improve the capability of people to utilize the knowledge, resources and skill to diversify asset, to access to information related to health and sanitation for improving human capital, enhancing agriculture production and reducing food insecurity.

It is actually an essential factor of sustainable development which cannot be achieved without a mentionable investment in education. It brings social development through enhancing productivity, making awareness and sense of development which ensures better individual and social life. In Bangladesh, there is no specific study on the educational attainment and it relates to economic development. The study shows that the contribution of education on economic development in developed countries is above $10 \%$, where it is $5.88 \%$ in Bangladesh in 2009. According to UNESCO [7], the GDP can be increased by increasing the investment in education in the long run. The educational expenditure is also increasing day by day in Bangladesh like 1.1\% was in 1975 which increased to $2.46 \%$ in 2001 subsequent GDP was $0.94 \%$ in 1980 but increased to 2732 billion in 2001 [6]. Similarly, GDP was $2.39 \%$ and increased to the 6149.4 billion in 2010 [16]. It shows that sustainable economic development cannot be gained without larges and long-term investment to the education sector. School dropout is a major barrier to achieve the targeted goal of economic development. Shahidul [30] reported that human capital and economic development largely depend on the investment in education by assessing the period of 1977 to 2004 in the GCE countries. Islam (2014) conducted on the same kind of study in India and reported that there was a positive relationship between educational growth and economic development. He conducted a study using time series data and used multivariate causality analysis using data from 1976 to 2003. According to Abuya et al. [33], since economic development is a key tool for reducing poverty and sustainable growth, it is largely depending on education and reducing dropout of a country like Bangladesh. According to Alliance for excellent education [13], the impact of high school dropout is more than three times of unemployed than college graduate and less than about $\$ 25,500$ of college per year by assessing US bureau of labour statistics, 2014. School dropout is not the only burden for the mainstream economy of a country but also for themselves a society. In the future, most of the job will be available for graduates but it will squeeze the job for dropout.

Education is an important tool for human capital. People without education are unaware of their responsibility as a citizen. Since human capital accelerates economic activity and development, so it is necessary to invest in developing human capital. Since education can directly influence entrepreneurship, employment opportunities, increasing productivity, women empowerment, and potential youth development through improving ability, skill, creativity for facing challenges, so it is directly related to economic development of a country. School dropout reduces literacy rate which reduces the ultimate economic growth of a country like Bangladesh. Literature survey shows that only education can improve the people's ability to diversify assets, access to information, health and sanitation, enhancing human capital, increasing social and economic progress. The cumulative impact of school dropout on the nation's economy is staggering [13]. Andrei et al. [37] found that the low level of the economic development, the share of education expenditures in GDP and labour market characteristics at the national level were the causes of school dropout of some countries in EU. School dropout creates a hindrance to ensuring education for all in Bangladesh. The study shows that the older child is more vulnerable to drop out in Bangladesh which means that average students in the higher class are more vulnerable than average students in the lower class. Sabates et al. [19] point out that age is a major factor of school dropout in some African countries. In some cases, the average is not a big problem at lower classes but with increasing age with grade increases vulnerability to dropout from school. Financial barriers are the most common barriers for school dropout in Bangladesh. Some studies show that lack of study material, inability to pay the fees, poor physical structure, teacher's absenteeism, poor teaching system and chronic poverty are the major factors of school dropout in Bangladesh. In Bangladesh, the dropout rate of boys $(66 \%)$ is higher than girls (34\%) [12]. It may be due to the intervention of government program especially a stipend program for girls' student. The feed for education program has a great impact on increasing the enrolment at the primary school level and reduces the risks of school dropout. Finally, literature survey shows that biased social practice, lack of quality education, opportunity cost, uncontrolled population growth, pregnancy of school girls, child labor, cost of schooling, migration, early marriage of girls, geographical isolation like riverbank area, island char areas, coastal areas and Haor areas and effects of close and distant friendships are the major causes of dropout from school in Bangladesh.

\section{POLICY RECOMMENDATION}

A single intervention is not enough to mitigate the big problem like school dropout in Bangladesh. Several practical actions should be taken by the concerned authority to solve the problem especially overage, social, economic, political and environmental barriers of school dropout. A holistic approach should be implemented in the long run for solving these problems. The study recommends the following strategies to minimize school dropout.

- Age should be considered at the time of enrollment. A campaign should be launched to aware the parents on admission time of the children. It will minimize the overage problem.

- Physical facility of a school should be ensured. The basic physical facilities like a well-equipped house, water, electricity, study materials, computer, laboratory and other daily necessities should be supplied properly to encourage the students and teachers to study and minimize school dropout.

- Too much examination should be eliminated. Because low mark, lower serial number, and failure encourage the children's mind to leave the school. The authority should be followed the education system of a developed countries like Japan, USA, and the UK and minimize the examination number with proper modification of assessment system with introducing auto promotion from 
grade to grade. Obviously, it will reduce the school dropout.

- Special programs should be introduced for the students and teachers who are attending the school in a specialized area which situated in a riverine island, flood-prone area, Haor and coastal areas and mountainous areas. Special incentives should be given to the teachers and related officials for residing in such remote areas. Because absenteeism of teachers and students are a common scenery of these areas. Some special school should be introduced where hard to reach especially in a flooded situation like boat school, and temporary mobile school.

- Monitoring should be ensured from the ministry of education to minimize corruption, absenteeism of teachers and students, maintaining age of admission, quality of education, extra-curricular activities and warning guardian about dropout vulnerable students. An integrated committee should be made by parents, local administration officials, teachers, and local representative to monitor these matters.

- Various dimensions of school dropout should be addressed by the concerned authority. The tendency of early marriages should be abolished through social mobilization and security for girl students should be ensured at educational institutions.

- The new school should be established with recruiting quality teachers considering the growth rate of population. Teacher-student ratio should be maintained for quality education. Scholarship and monthly stipend should be increased for needy and financially insolvent students [38].

- Demand and market-oriented curriculum should be introduced for quality and job-oriented education. The monitoring system should bring under ICT so that anyone can monitor the whole system from anywhere. The private sector should be encouraged to invest in the education sector realizing the economic benefit of the country.

- The current scholarship program has some difficulties to meet the needs of remote area students. These problems should be addressed immediately and more stipends should be awarded to the children. It needs to be ensured that stipends are given to those who actually need it. School-feeding program (lunch) should be helpful to those remote areas.

- Communication is a big problem for geographically isolated areas like riverine islands, mountains, and coastal areas. Easy transport system should be facilitated by the GOB to the students as well as teachers.

\section{CONCLUSION}

The paper examines the economic effect of school dropout and associated factors for school dropout in Bangladesh. This article reveals that school dropout is negative related to economic development in Bangladesh. The study also explores that chronic poverty, parent's unwillingness, financial problem, school's poor infrastructure, biased social practice, lack of quality education, geographic isolation, unequal access to education, overload classroom, carelessness of teacher and security problems for girls are major causes of school dropout in Bangladesh. There is no other way but to reduce dropout to reach the goal of ensuring education for all. A government organization (GO) and Non-Government Organization (NGO) collaboration is necessary to address this problem. The study suggests that free education program, providing more scholarship at primary and secondary level, reducing paid coaching culture, lessening cost of private school, raising awareness of parents by teacher-parents relationship, improving school's infrastructure, stopping early marriage of girls, ensuring equal access to education, merging various curriculum into one/two unique system, providing quality training for teachers, provision of all related facilities should be ensured by the government.

\section{REFERENCES}

[1] UNESCO, "A guide for ensuring inclusion and equity in education," 2017.

[2] S. R. Nath, "Factors influencing primary students' learning achievement in Bangladesh," Res. Educ., vol. 88, no. 1, pp. 50-63, 2012.

[3] M. N. I. Sarker, Poverty of Island Char Dwellers in Bangladesh, Dominica Publishing House, Germany, 2016.

[4] G. Kruss, S. McGrath, I. harm Petersen, and M. Gastrow, "Higher education and economic development: The importance of building technological capabilities," Int. J. Educ. Dev., vol. 43, pp. 22-31, 2015.

[5] S. J. Cabus, An Economic Perspective on School Dropout Prevention using Microeconometric Techniques, 2013.

[6] M. M. C. Shohel, "Childhood Poverty and Education in Bangladesh: Policy implications for disadvantaged children," vol. 4, no. 2, pp. 77-94, 2012.

[7] UNESCO, "A growing number of children and adolescents are out of School as aid fails to meet the mark," Stat. Educ. All Glob. Monit. Rep., no. July, pp. 1-13, 2015.

[8] R. Sabates, A. Hossain, and K. M. Lewin, "School drop out in Bangladesh: New insights from longitudinal evidence," no. 49, 2010.

[9] H. Yi et al., "Exploring the dropout rates and causes of dropout in upper-secondary technical and vocational education and training (TVET) schools in China," Int. J. Educ. Dev., vol. 42, pp. 115-123, 2015.

[10] L. A. Choudhary AI, "Economic effects of student dropouts: A comparative study," J. Glob. Econ., vol. 3, no. 2, pp. 2-5, 2015.

[11] International Creative Associates, "School dropout prevention pilot program: Review of the literature," 2011.

[12] A. Asad, "Bangladesh education: Practices and challenges," 2009.

[13] Alliance for Excellent Education, "The high cost of high school dropouts: The economic case" alliance for excellent education," 2018.

[14] World Bank, "Realizing the promise of education for development: World development report 2018 themes and emerging messages," 2017.

[15] S. M. Shahidul, "Marriage market and an effect on girls 'school dropout in Bangladesh," J. Altern. Perspect. Soc. Sci., vol. 4, no. 2, pp. 552-564, 2012.

[16] BANBEIS, "Statistical profile on education in Bangladesh," Dhaka, Bangladesh, 2016.

[17] F. Prevatt and F. D. Kelly, "Dropping out of school: A review of intervention programs," J. Sch. Psychol., vol. 41, no. 5, pp. 377-395, 2003.

[18] M. S. I. Sarker, "The Impact of socio-cultural factors on dropout rates for girls at the secondary school level in Bangladesh," Tohoku University, 2013.

[19] R. Sabates, A. Hossain, and K. M. Lewin, "School drop out in Bangladesh: Insights using panel data," Int. J. Educ. Dev., vol. 33, no. 3, pp. 225-232, 2013.

[20] T. Hochfeld, L. Graham, L. Patel, J. Moodley, and E. Ross, "Does school breakfast make a difference? An evaluation of an in-school breakfast programme in South Africa," Int. J. Educ. Dev., vol. 51, pp. $1-9,2016$.

[21] S. J. Cabus and K. Witte, "Does school time matter? On the impact of compulsory education age on school dropout," Economics of Education Review, vol. 30, no. 6. pp. 1384-1398, 2011. 
[22] J. Cristia, A. Czerwonko, and P. Garofalo, "Does technology in schools affect repetition, dropout and enrollment? Evidence from Peru," J. Appl. Econ., vol. 17, no. 1, pp. 89-111, 2014.

[23] A. U. Ahmed, "Impact of feeding children in school: Evidence from Bangladesh," Int. Food Policy Res. Inst., vol. 2033, pp. 10-20, 2004

[24] H. Sajjad, M. Iqbal, M. A. Siddiqui, and L. Siddiqui, "Socio-economic determinants of primary school dropout: Evidence from South East Delhi, India," Eur. J. Soc. Sci., vol. 30, no. 3, pp. 391-399, 2012.

[25] A. S. Graeff-Martins, S. Oswald, J. Obst Comassetto, C. Kieling, R. Rocha Gonçalves, and L. A. Rohde, "A package of interventions to reduce school dropout in public schools in a developing country: A feasibility study," Eur. Child Adolesc. Psychiatry, vol. 15, no. 8, pp. 442-449, 2006.

[26] M. N. I. Sarker, "Causes and possible solutions of seasonal food insecurity (Monga) perceived by char dwellers in Bangladesh," Int. J. Ecol. Dev. Res., vol. 1, no. 1, pp. 2-9, 2016.

[27] M. N. U. Khan, E. A. Rana, and M. R. Haque, "Reforming the Education System in Bangladesh: Reckoning a Knowledge-based Society," World J. Educ., vol. 4, no. 4, pp. 1-11, 2014.

[28] Create, "Preventing dropout in create Bangladesh," Create Bangladesh Policy Brief 6, 2011.

[29] T. Yancey, "The Multidimensionality of schoolgirl dropouts in rural Bangladesh," 2015.

[30] S. M. Shahidul, "Parents' class background and hypergamy in the marriage market of Bangladesh: Does the dowry affect school dropout among girls?" Asia-Pacific Educ. Res., vol. 23, no. 3, pp. 709-715, 2014.

[31] S. S. Zuilkowski, M. C. H. Jukes, and M. M. Dubeck, “I failed, no matter how hard I tried': A mixed-methods study of the role of achievement in primary school dropout in rural Kenya," Int. J. Educ. Dev., vol. 50, pp. 100-107, 2016.

[32] M. N. Islam, "Riverbank erosion induced migration by the char-dwellers in Bangladesh: Towards a better strategy," Asian J. Environ. Disaster Manag. - Focus. Pro-active Risk Reduct. Asia, vol. 4, no. 3, p. 243, 2013.

[33] B. A. Abuya, E. O. Onsomu, D. K. Moore, and J. Sagwe, “A phenomenological study of sexual harassment and violence among girls attending high schools in urban slums, Nairobi, Kenya," J. Sch. Violence, vol. 11, no. 4, pp. 323-344, 2012.

[34] B. G. Gibbs and T. B. Heaton, "Drop out from primary to secondary school in Mexico: A life course perspective," Int. J. Educ. Dev., vol. 36 , pp. 63-71, 2014.

[35] R. Islam, "Education and economic growth in bangladesh - An econometric study," IOSR J. Humanit. Soc. Sci., vol. 19, no. 2, pp. 102-110, 2014.
[36] BBS, "Education scenario in Bangladesh: Gender perspective," 2017.

[37] T. Andrei, D. Teodorescu, and B. Oancea, "Quantitative methods used to identify the causes of school dropout in EU countries," Procedia Soc. Behav. Sci., vol. 31, no. 2011, pp. 188-192, 2012.

[38] M. Ahmmed, U. Sharma, and J. Deppeler, "Variables affecting teachers' attitudes towards inclusive education in Bangladesh," J. Res. Spec. Educ. Needs, vol. 12, no. 3, pp. 132-140, 2012.

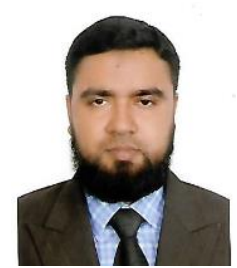

Md Nazirul Islam Sarker is a $\mathrm{PhD}$ candidate of School of Public Administration, Sichuan University, Chengdu, China. He completed his bachelor of science in agriculture and the master in agricultural extension education from Bangladesh Agricultural University. He also completed the MBA from Commonwealth of Learning. He also completed two diplomas in banking and Islamic banking. His research interest includes poverty, food security, livelihood and climate changes and education economy. He has published a couple of scientific articles and one book on Poverty of Island Char Dwellers in Bangladesh. He is a member of several professional bodies. Mr. Sarker is now working as an editorial board member of several social sciences and public administration journals.

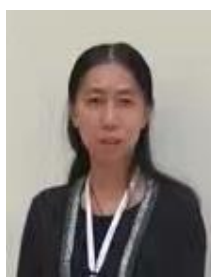

Min Wu is a professor in the School of Public Administration, Sichuan University, Chengdu, China. Her research interests include leadership, justice, trust, identity, empowerment and Chinese management issues. She has published a couple of scientific articles in Management and Organization Review, Journal of Management Psychology and Chinese Management Studies and served as a reviewer of coupled reputed journals and conferences. She is now supervising a number of $\mathrm{PhD}$ students.

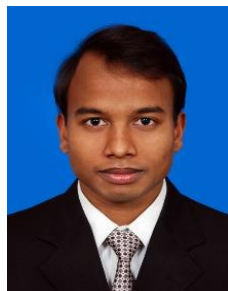

Md Altab Hossin received the MSc from University of Electronic Science and Technology of China. Currently, he is working as a $\mathrm{PhD}$ degree candidate at the School of Management and Economics, University of Electronic Science and Technology of China (UESTC). His research interests include e-business, information systems \& management, data mining techniques, and consumer behaviour. $\mathrm{He}$ has published couple of scientific articles in reputed journals and conferences. 